\title{
Heterologous expression of biologically active Mambalgin-1 peptide as a new potential anticancer, using a PVX-based viral vector in Nicotiana benthamiana
}

\author{
Ghaffar Khezri ${ }^{1}$ Bahram Baghban Kohneh Rouz ${ }^{1} \cdot$ Hamideh Ofoghi ${ }^{2} \cdot$ Seyed Javad Davarpanah ${ }^{3}$ (I)
}

Received: 19 August 2019 / Accepted: 30 April 2020 / Published online: 29 June 2020

C) Springer Nature B.V. 2020

\begin{abstract}
Mambalgin-1 is a peptide that acts as a potent analgesic through inhibiting acid-sensing ion channels (ASIC) in nerve cells. Research has shown that ASIC channels are involved in the proliferation and growth of cancer cells; therefore, Mambalgin-1 can be a potential anti-cancer by inhibiting these channels. In the present study, the Nicotiana benthamiana codon optimized Mambalgin-1 gene was synthesized and cloned in PVX (potato virus X) viral vector. The two cultures of Agrobacterium containing Mambalgin-1 and P19 silencing suppressor genes were co-agroinfiltrated into $N$. benthamiana leaves. Five days post infiltration, the production of recombinant Mambalgin-1 was determined by western blotting. For biological activity, MTT (3(4, 5-dimethylthiazole-2-yl)-2, 5-diphenyltetrazolium bromide) was analyzed for the cytotoxicity recombinant Mambalgin-1 from the transformed plants on nervous (SH-SY5Y) and breast (MCF7) cancer cells. The results showed that the plants expressing open reading frame of Mambalgin-1 showed recombinant 7.4 kDa proteins in the entire plant extract. In the MTT test, it was found that Mambalgin-1 had cytotoxic effects on SH-SY5Y cancer cells, yet no effects on MCF7 cancer cells were observed. According to the results, the expression of the biologically active recombinant Mambalgin-1 in the transformed plant leaves was confirmed and Mambalgin-1 can also have anti-cancer (inhibition of ASIC channels) potential along with its already known analgesic effect.
\end{abstract}

\section{Key message}

The Mambalgin-1 transiently expressed in Nicotiana benthamiana plant and its anti-cancer effect on SH-SY5Y nerve cancer cells, since ASIC channels are involved in the proliferation of cancer cells, was confirmed.

Communicated by Degao Liu.

Electronic supplementary material The online version of this article (doi:https://doi.org/10.1007/s11240-020-01838-x) contains supplementary material, which is available to authorized users.

Bahram Baghban Kohneh Rouz

bahramrouz@yahoo.com

$\triangle$ Seyed Javad Davarpanah davarpanah@bmsu.ac.ir

1 Department of Plant Breeding and Biotechnology, University of Tabriz, Tabriz, Iran

2 Department of Biotechnology, Iranian Research Organization for Science and Technology, Tehran, Iran

3 Applied Biotechnology Research Center, Baqiyatallah University of Medical Sciences, Tehran, Iran 
Keywords Mambalgin-1 · Transient expression $\cdot$ Nicotiana benthamiana $\cdot$ Agroinfiltration $\cdot$ Acid sensing ion channels (ASICs) · Cancer

\section{Introduction}

In 2012, Diochot et al. discovered a pair of peptides, mambalgin-1 and mambalgin-2, from the venom of black mamba snakes (Dendroaspis polylepsis) which had a potent analgesic effect on central and peripheral nervous system upon injection that can be as strong as morphine (Diochot et al. 2012). Mambalgin- 1 and mambalgin- 2 are composed of 57 amino acids that differ by one amino acid at position 4 . The mambalgins are potent blockers of acid-sensing ion channels (ASICs), inhibiting them by shifting the $\mathrm{pH}$-dependence of activation to more acidic $\mathrm{pH}$, decreasing their apparent affinity for protons (Diochot et al. 2016). Mambalgins have analgesic effects without side associated effects such as naloxone susceptibility, respiratory distress and much less tolerance than morphine in mice (Diochot et al. 2016; Salinas et al. 2014). In addition to pain perception, ASICs have been implicated in the proliferation and migration of cancer cells, fear-anxiety-related behavior, and sensory transduction (Baron and Lingueglia 2015; Kapoor et al. 2009; Wu et al. 2017a). Because of the role that ASIC channels have in pain perception, neurological diseases, and proliferation of cancerous cells (Baron and Lingueglia 2015; Kapoor et al. 2009; Wu et al. 2017a; Xiong et al. 2008), Mambalgins can be used as inhibitors of these channels in pharmacological research and encourage researchers to develop neurological, analgesic and anti-cancer drugs. After the discovery of Mambalgins (Diochot et al. 2012), various studies have been performed related to the association between these peptides and ASICs (Diochot et al. 2016; Mourier et al. 2016; Salinas et al. 2014). Owing to the expression of valuable therapeutic recombinant proteins; plants and plant cells have advantage over other methods of recombinant protein production due to the high biomass, scalability, cost-effectiveness and low risk of contamination by human or animal pathogens (Loh et al. 2017; Margolin et al. 2018). Transient expression systems requires less time and cost for the production of recombinant protein, as in transient expression systems, production of recombinant protein occurs shortly after several days of gene delivery, while in stable expression systems it takes months to generation, selection and confirmation of stable transgenic plant lines, also these systems are not affected by position effects (Fahad et al. 2015; Leuzinger et al. 2013; Yamamoto et al. 2018). The former systems are the more favorable choice due to the simplicity and feasibility of rapid protein expression, removal of tissue culture, cost of regeneration and easy scalability for industrial production (Moghaddam et al. 2014). In recent years, therapeutic proteins have been produced by transient expression systems for various diseases such as influenza (various types), hepatitis B, West Nile, Severe acute respiratory syndrome (SARS), Plague and Smallpox; some of these proteins are on market, while some others are undergoing clinical trials (Hefferon 2017). The success and effectiveness of transient expression systems depends on several factors such as codon-optimization of the heterologous gene according to plant codon adaptation index (CAI) (Love et al. 2012; Mohammadzadeh et al. 2014), selection of the proper expression vector which includes application of efficient promoter (Buyel et al. 2013; Hefferon 2017, 2012) and efficient inhibition of the gene silencing phenomenon which suppresses the expression of foreign genes in plants (Obembe et al. 2011). In transient expression systems, viral vectors are conducive to the production of recombinant proteins, since these vectors have an easy genetic manipulation and provide a high level of recombinant protein expression over a short time (Kopertekh and Schiemann 2019; Rybicki 2018). The use of post-transcriptional gene silencing (PTGS) suppressors such as P19 can increase the expression level of foreign genes in transient expression systems (Mohammadzadeh et al. 2014, 2016). In the present study, PVX (potato virus $X$ ) vector was used to assess the plant expression of Mambalgin-1 gene by co-agroinfiltration with viral suppressor P19 in $N$. benthamiana; we further determined biological activity of this recombinant protein on nervous (SH-SY5Y) and breast (MCF7) cancer cells.

\section{Materials and methods}

\section{Codon optimization of mambalgin-1 and construction of the vector}

For codon optimization, the desired protein sequence was used and back-translated from amino acid to DNA sequence (Supplementary Fig. 1) using the Visual Gene Developer software (VGD) based on $N$. benthamiana Codon Usage from Kazusa Database (Jung and McDonald 2011; Nakamura et al. 1998). For codon optimization of the target sequence, several factors were considered such as i) codon optimization according to the CAI of nuclear-encoded genes of N. benthamiana (Carbone et al. 2003), ii) removal of sequences that cause mRNA instability, iii) addition of signal peptide derived from pathogenesis-related protein Q of Nicotiana tabaccum (Payne et al. 1990) (Amino acid sequence: MEFSGSPMALFCCVFFLFLTGSLA (Uniprot accession number: P17514), Nucleotide sequence: ATG GAGTTCTCTGGTTCTCCTATGGCATTGTTCTGTTGT 
GTATTCTTCCTCTTCCTTACTGGTTCTCTTGCT) to avoid methionine addition at $5^{\prime}$ and the possibility of cutting this signal peptide from Mambalgin-1 by SignalP 4.1 Server (Nielsen 2017; Petersen et al. 2011), iv) addition of hexa histidine (6xHis)-tag for nickel affinity purification at the $3^{\prime}$ site, v) checking and changing the polyadenylation signals, vi) detection of enzyme restriction sites in the target sequence for the employed restriction enzymes, vii) addition of stop codon at the $3^{\prime}$ end and modification of the hidden stop codon between sequence codons, and viii) addition of ClaI, SalI, XbaI and SacI restriction sites at both ends of the gene. The foregoing process of codon optimization was done with Visual Gene Developer (Jung and McDonald 2011) and MEGA4 (Tamura et al. 2007) softwares. Amino acid and optimized nucleotide sequences have been recorded and published in gene bank (accession numbers QGP71486 and MN646218, respectively). The plant-optimized Mambalgin-1 for recombinant expression in $N$. benthamiana was synthesized and cloned into the ClaI/SalI sites of PVX-GW vector, under the control of a duplicated PVX coat protein subgenomic promoter (CPP).

\section{Transformation of Agrobacterium tumefaciens by plant expression vector}

Agrobacterium tumefaciens strain GV3101 was transformed with the PVX-Mambalgin-1 via the standard freeze-thaw protocol (Weigel and Glazebrook 2006). Subsequently, transformed Agrobacterium cells were selected on plates containing $100 \mu \mathrm{g} / \mathrm{ml}$ rifampicin (RIF) and $50 \mu \mathrm{g} / \mathrm{ml} \mathrm{kana-}$ mycin (KAN) and incubated for $72 \mathrm{~h}$ at $28^{\circ} \mathrm{C}$. Transformed Agrobacterium was confirmed by gene-specific colony PCR using forward (5'-CACCAGCTAGCATCGATTC-3') and reverse (5'-GGTCGACGAGCTCTTATTAATG-3') specific primers. The primers were designed with the Oligo Primer Analysis Software version 7 (Rychlik 2007). P19 was received as pCamBia1300-TBSVp19 expression vector gifted by Dr. Won-Joong Jeong (Korea Research Institute of Biosience and Biotechnology). Subcloning of p19 was mentioned in Ahn et al 2011 (Ahn et al. 2011).

\section{Plant growth}

Growth and germination of $N$. benthamiana were performed in cocopeat in an environment of $25{ }^{\circ} \mathrm{C}$ temperature, and $60 \%$ humidity with a $16 / 8 \mathrm{~h}$ day/night cycle. The plants were feed by $1 / 2$ NPK (20:20:20) with a concentration of $1.84 \mathrm{~g} / \mathrm{l}$ every $2-3$ days during germination and growth. After 4 weeks, the plants were transferred to larger pots $(1000 \mathrm{ml})$ with cocopeat and maintained from 6 to 7 weeks in the above condition except that humidity reduced to $50 \%$.
Co-agroinfiltration of $N$. benthamiana leaves by $\mathrm{p} 19$ silencing-suppressor

To suppress the silencing of the target gene expression in N. benthamiana, Agrobacterium strain GV3101 containing PVX-Mambalgin-1 and Agrobacterium harboring pCamBia1300-TBSVp19 were co-infiltrated together. For the preparation of Agrobacterium mixture, the overnight cultures of Agrobacterium (20 ml, Luria broth (LB) medium containing $10 \mathrm{~g} / \mathrm{l} \mathrm{NaCl}, 10 \mathrm{~g} / \mathrm{l}$ Peptonase Casein, $5 \mathrm{~g} / \mathrm{l}$ yeast, $100 \mu \mathrm{g} / \mathrm{ml}$ RIF and $50 \mu \mathrm{g} / \mathrm{ml} \mathrm{KAN)} \mathrm{harboring} \mathrm{PVX-Mambalgin-} 1$ and other harboring pCamBia1300-TBSVp19, were refreshed (in $80 \mathrm{ml} \mathrm{LB}$ medium, $28^{\circ} \mathrm{C}, 200 \mathrm{rpm}$ ) until reaching OD600 of 2 . The culture were centrifuged at $22^{\circ} \mathrm{C}$ and $5000 \times g$ for $10 \mathrm{~min}$ and supernatant was discarded. The pellets separately resuspended at $400 \mathrm{ml}$ induction medium $(1 \times \mathrm{MS}$, $10 \mathrm{mM}$ MES, $200 \mu \mathrm{M}$ Acetosyringone, $2 \%$ Sucrose) and after $3 \mathrm{~h}$ incubation $\left(28{ }^{\circ} \mathrm{C}, 200 \mathrm{rpm}\right)$ were mixed with $1: 1$ ratio (Shamloul et al. 2014). Mock agroinfiltration was performed as above except using PVX-GW blank vector instead of recombinant Mambalgin-1 containing vector. After inverting the aerial part of the whole six weeks plant in the bacterial mixture, the 100 mbar vacuum was applied, until removing all air bubbles from the leaves and by releasing, Agrobacterium infiltrated into the plant tissue and this step was repeated to ensure complete infiltration. The infiltrated plants were washed with distilled water and were placed in germinator with $16: 8 \mathrm{~h}$ light/dark photoperiod, $25^{\circ} \mathrm{C}$ and $50 \%$ humidity condition.

\section{Total protein preparation}

Five days after agroinfiltration, the infiltrated leaves were harvested, frozen in liquid nitrogen, and were ground into a fine powder using a mortar and pestle. Subsequently, $500 \mu \mathrm{l}$ extraction buffer containing $15 \%$ sucrose, $60 \mathrm{mM}$ Tris-HCl (pH 6.8), 2 mM Ethylene diamine tetra acetic acid (EDTA) (pH 8), $0.1 \%$ Sodium dodecyl sulfate (SDS), $1 \mathrm{mM}$ Ethylene glycol tetra acetic acid (EGTA), $4 \mathrm{mM}$ Dithiothreitol (DTT), and $1 \mathrm{mM}$ Phenyl methyl sulfonyl fluoride (PMSF) was added per $100 \mathrm{mg}$ of leave powder. The suspension was centrifuged at $5000 \mathrm{xg} / 4{ }^{\circ} \mathrm{C}$ for $10 \mathrm{~min}$ to separate the protein and supernatant was transferred to a fresh tube. The centrifugation was performed again under the same conditions to pellet any carryover leaf debris. The supernatant was divided into small vials and immediately transferred to ice. The concentration of total protein was estimated using the Bradford (Bradford 1976) assay by bovine serum albumin (BSA) as standard. 


\section{Western blot analysis}

Non-reducing Sodium Dodecyl Sulfate Poly-Acrylamide Gel Electrophoresis (SDS-PAGE) was prepared for western blotting. The extracted total soluble protein (TSP) from agroinfiltrated with PVX-Mambalgin-1 and agroinfiltrated with PVX vectore alone (without Mambalgin-1) as a negative control, using the Laemmli buffer (Laemmli 1970) were loaded in each well. $30 \mu \mathrm{g}$ total protein was loaded (based on Bradford's assay) onto a 12\% SDS-acrylamide gel electrophoresed, and the protein bands were transferred to the nitrocellulose at 80 vlolts for $120 \mathrm{~min}$. Nitrocellulose paper was coated with a blocking solution (PBS buffer $(1 \times)$ containing 5\% skim milk) for $90 \mathrm{~min}$ at room temperature. After 3 times washing by wash buffer (PBS buffer $(1 \times)$ containing 0/05\% TWEEN 20), nitrocellulose paper was incubated with mouse Anti-His-tag (dilution 1:2000 in PBS buffer containing 3\% skim milk; Biolegend Inc.) for $120 \mathrm{~min}$ at room temperature and through slow shaking. Then, washing was done as was mentioned above and the membrane was incubated with the goat anti-mouse IgG/HRP (dilution 1:2000 in PBS buffer containing 3\% skim milk; Sigma Inc.) conjugated HRP enzyme for $1 \mathrm{~h}$ at room temperature. Again, the membrane was washed by wash buffer three times for $5 \mathrm{~min}$. Finally, the membrane was incubated, in staining buffer (0.05\% DAB (3,3'-Diaminobenzidine), $0.015 \%$ $\mathrm{H} 2 \mathrm{O} 2,0.01 \mathrm{M}$ PBS, $0.015 \% \mathrm{NiCl} 2$ ). For staining stops, the membrane was placed, in distilled water.

\section{Quantitative measurement of the recombinant protein expression by His-Tag ELISA Detection Kit in TSP}

To measure the amount of Mambalgin-1 in TSP, the HisTag ELISA Detection method (based on competitive ELISA method) was performed using TSPs extracted from transformed leaves (commercial His-Tag ELISA Detection Kit; GeneScript, cat.No: Loo436, USA). The TSP was diluted to $15 \mu \mathrm{g} / \mathrm{ml}$. Then $50 \mu \mathrm{l}$ of each sample added to each well. Afterward, $50 \mu \mathrm{l}$ of Anti-His Monoclonal Antibody added to all the wells immediately and incubated at room temperature $\left(24-25^{\circ} \mathrm{C}\right)$ for $30 \mathrm{~min}$. After 4 washes of plates by $1 \times$ wash solution, $100 \mu$ of Antibody Tracer added to every well and Incubated at room temperature for $30 \mathrm{~min}$. $100 \mu$ of (3,3',5,5'-Tetramethylbenzidine) TMB Substrate added to every well after 4 washing repeats and incubated for 10-15 min at room temperature. Then $50 \mu \mathrm{l}$ of Stop Solution added and the absorbance read at $450 \mathrm{~nm}$. The His-Tag Standard which is available in the Kit and protein extracted from Wild-type used as the positive and negative controls, respectively.

\section{Biological activity of Mambalgin-1 in TSP}

Similar to the MTT test performed by Moghaddam et al. (2014) $50 \mathrm{mg}$ of MTT (3(4,5-dimethylthiazole-2-yl)2,5-diphenyltetrazolium bromide) powder was completely dissolved in $10 \mathrm{ml}$ of distilled deionized water and filtered through $0.2 \mu \mathrm{m}$ filter, which was then aliquoted into $1.5 \mathrm{ml}$ volumes and stored at $-20{ }^{\circ} \mathrm{C}$. SH-SY5Y and MCF7 cancer cells were harvested in a previously-cultured flask; after collecting in a falcon tube and centrifuging at $300 \times g$ for $10 \mathrm{~min}$, a total cell count of $5 \times 10^{5}$ cells $/ \mathrm{ml}$ was calculated. After addition of MTT to each well of the plate; 10,000 cell/ well poured into every 96 well microplates. Each well contained $100 \mu \mathrm{l}$ of cell culture and total protein, where the total protein in each row was serially diluted from wells to a ratio of $1 / 2$. The test performed in 3 replicates and the medium was incubated at $37{ }^{\circ} \mathrm{C}$ and $5 \% \mathrm{CO}_{2}$ for $48 \mathrm{~h}$. To calculate cytotoxic RPMI (Roswell Park Memorial Institute medium), the medium was used as a negative control. After incubation, $10 \mu \mathrm{l}$ of MTT solution (final concentration of $0.5 \mu \mathrm{g} /$ $\mathrm{ml}$ ) was added to each well, and incubated at $37{ }^{\circ} \mathrm{C}$ and $5 \%$ $\mathrm{CO}_{2}$ for 6-4 h. In order to observe the formation of purple crystals with a microscope, the supernatant was collected slowly and $100 \mu \mathrm{l}$ of crystalline solvent solution (Dimethyl sulfoxide (DMSO)) was added; the crystals dissolved by pipetting. After 10 to $20 \mathrm{~min}$, the OD was read at $570 \mathrm{~nm}$ by ELISA Reader and the cytotoxicity was calculated as 1- (AT/ $\mathrm{AC}) \times 100$, where AT and AC are absorbances of treated and control cells, respectively.

\section{Protein purification}

For purification, the chelating and reducing reagent (DTT, Dithioerythritol (DTE), tris (2-carboxyethyl) phosphine (TCEP), EDTA, and EGTA) of protein extraction buffer of TSP that cause to detach the metal ion (Co or $\mathrm{Ni}$ ) from chromatography resin was removed from TSPs using dialysis tubing (Sigma-Aldrich Inc) (Unger and Peleg 2012). In the next step, add $1.5 \mathrm{ml}$ TALON® Metal Affinity Resin (Clontech Inc.) to a $10 \mathrm{ml}$ tube and pellet the resin by centrifugation at $4{ }^{\circ} \mathrm{C}$ and $500 \times g$ for 3 min and carefully decant the storage buffer. The resin was resuspended in $5 \mathrm{CV}$ of distilled water and water removed as above. Wash the resin by resuspending in $1 \mathrm{CV}$ binding buffer $(50 \mathrm{mM} \mathrm{Na} 2 \mathrm{HPO} 4$, $300 \mathrm{mM} \mathrm{NaCl}, \mathrm{pH} 8.0$ ) supplemented with $10 \mathrm{mM}$ imidazole). Wash buffer was removed as above and wash step was repeated again. Dialysate TSP added to the Cobalt Chelating Resin in 2:1 ratio and incubated with mechanical rotation for 15-20 min at room temperature. The resin was pellet by centrifugation at $4{ }^{\circ} \mathrm{C}$ and $500 \times g$ for 3 min and carefully decanted the storage buffer as before. Elution buffer $(50 \mathrm{mM}$ $\mathrm{Na}_{2} \mathrm{HPO}_{4}, 300 \mathrm{mM} \mathrm{NaCl}, 250 \mathrm{mM}$ Imidazole, $\mathrm{pH}$ 8) added to the resin in $2: 1$ ratio and centrifuged at $4{ }^{\circ} \mathrm{C}$ and $500 \times g$ 
for $3 \mathrm{~min}$. Collect the eluate as above and repeat the elution two times. To remove the imidazole used to separate the recombinant protein from the resin, after the purification of the recombinant protein, dialysis was performed again as above.

\section{Quantitative measurement and biological activity of purified Mambalgin-1}

Purified protein concentration was measured using His-Tag ELISA Detection (similar to the previous step but negative control was dialyze buffer). Finally, the effect and biological activity of purified Mambalgin-1 on the SH-SY5Y and MCF7 cancer cells was evaluated by MTT test as above.

\section{Statistical analysis}

Statistical analysis of MTT test was performed using statistical analysis software (SAS) and Duncan test (Institute 2012). Differences at $99 \%$ level were considered significant.

\section{Results and discussion}

\section{Codon optimization of Mambalgin-1 for efficient expression in $\mathbf{N}$. benthamiana}

Sequences “ATAGAT" (nucleotides 230-235), "TTTTTT " (nucleotides 29-34), “TTTTTTTT" (nucleotides 41-48) and "GGTAAG" were modified as mRNA destabilizing (Brendel et al. 1998; Narsai et al. 2007) sequences (Supplementary Fig. 1). Hidden stop codons between main codons were changed such as "TGA" (nucleotides 204, 198 and 228), "TAA" (nucleotides 75, 93, 135, 162, 210, 213, 237 and 240) and "TAG" (nucleotides 112 and 153) (Supplementary Fig. 1). GC content and the value of the effective number of codons (Nc) from 30.33 and 12.59 to 39.32 and 18.58, respectively (Supplementary Fig. 2). Also, the CAI decreased from 0.99 to 0.85 (Supplementary Fig. 2). SignalP 4.1 Server (Nielsen 2017; Petersen et al. 2011) results shows that, the cut will occur precisely between positions 24 and 25 of the corresponding protein, releasing Mambalgin-1 from the signal peptide (Supplementary Fig. 3). The presence of methionine at the beginning of the gene is essential for translation but in the mature form of Mambalgin-1, there is no methionine at N-terminus. In a study on Pathogenesis-Related (PR) Proteins P and Q in N. tabaccum, it was observed that the 24-amino acid signal peptide was removed from purified Pathogenesis-Related-Q (PR-Q) to leave a mature one (Payne et al. 1990); therefore, the insertion of this signal at the N-terminal of the non-N-terminal methionine proteins can compensate for the lack of methionine. Since the addition of methionine at the beginning of the recombinant protein has an adverse effect on stability and function (Liao et al. 2004), the addition of methionine at the N-terminal is not desirable. Accordingly, we decided to add signal peptide (derived from PR-Q) (Payne et al. 1990) at $5^{\prime}$ of Mambalgin-1 gene to make up for the lack of methionine; through removing the signal peptide, the mature and original Mambalgin-1 was obtained. Since GC content is important in codon usage and more GC content will enhance protein expression (Barahimipour et al. 2015; Hellens et al. 2000), it was increased from 30.33 to 39.32 (Supplementary Fig. 2) (Fig. 1).

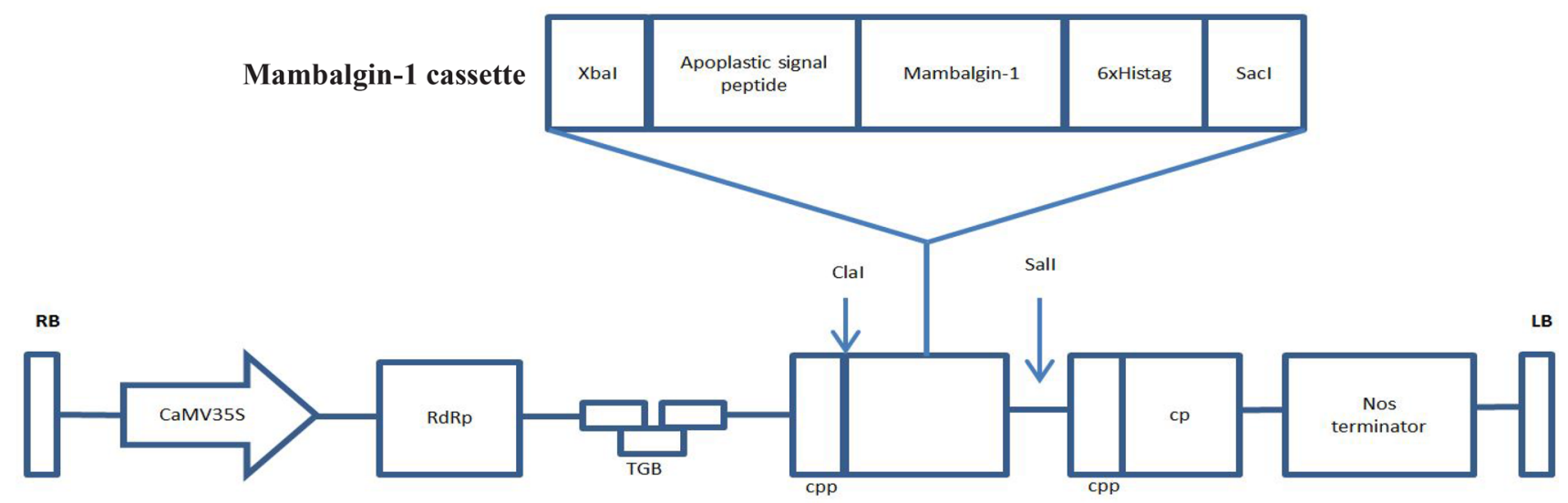

T-DNA of PVX-GW Vector

Fig. 1 Schematic diagram of the constructed PVX-Mambalgin-1 cassette: The synthetic optimized gene was inserted into the ClaI/SalI sites of PVX-GW vector under the control of duplicated PVX-coat protein subgenomic-promoter (CPP) 
Western blotting analysis

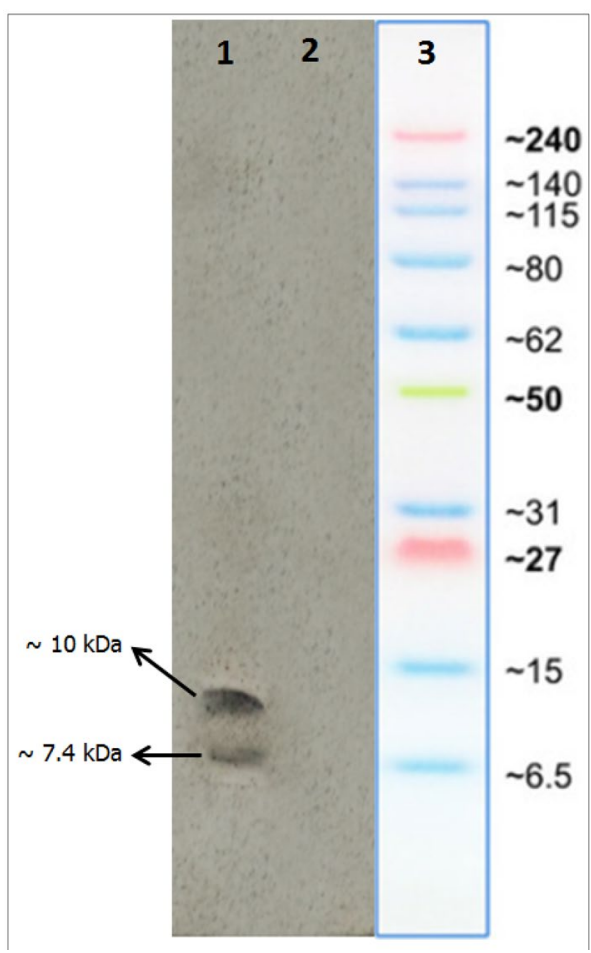

Fig. 2 Western blotting: lane 1: leaves agroinfiltrated with PVXMambalgin-1, lane 2: leaves agroinfiltrated with PVX vector alone (without Mambalgin-1), lane 3: protein ladder, in lanes 1 and 2, $30 \mu \mathrm{g}$ of plant TSP were applied in each lane. The appearance of the doublet bands (indicated arrows) could be due to the presence of the Mambalgin-1 with a signal peptide $(10 \mathrm{kDa})$ and no signal peptide $(7.4 \mathrm{kDa})$

Western blot analysis of Mambalgin-1 expression in $N$. benthamiana leaves

Western blotting using anti-histidine-tag and goat antimouse IgG/HRP indicated that the expression of Mamabalgin-1 in $N$. benthamiana produced two distinct protein bands. According to the ladder proteins, the molecular mass of the observed bands are about $10 \mathrm{kDa}$ and $7.4 \mathrm{kDa}$. The existence of these two bands shows that the signal peptide in the expressed protein exists in either cut $(7.4 \mathrm{kDa})$ or uncut $(10 \mathrm{kDa})$ forms. Bradford method estimated the TSP concentration to be $3.64 \mathrm{mg} / \mathrm{ml}$. Western results in Fig. 2 show that the signal peptide was not completely separated from Mambalgin-1, which was expressed either with $(\sim 10 \mathrm{kDa})$ or without a signal peptide $(\sim 7.4 \mathrm{kDa})$. Because this signal is apoplastic (Payne et al. 1990), certain proteins were able to enter the apoplastic space after cutting the signal peptide; others, however, did not have the opportunity to enter apoplastic space or were synthesized in the translation process.

\section{Quantitative measurement of the recombinant protein by His-Tag ELISA in samples of TSP and purified protein}

Expression of the recombinant protein further quantitatively measured by His-Tag ELISA Detection (Fig. 3) and the concentration of Mambalgin-1 in TSP and fresh leaf tissue estimated at $165 \mu \mathrm{g} / \mathrm{ml}$ and $0 / 825 \mathrm{~g} / \mathrm{kg}$ respectively. ELISA analysis of transiently expressed Mambalgin-1 from the total protein extraction of infiltrated leaves confirmed the expression of Mambalgin-1, specifically recognized by the conjugated anti-His-tag antibody. After the purification step, the purified Mambalgin-1 protein confirmed by His-Tag ELISA

Fig. 3 Quantification and Confirmation of recombinant Mambalgin-1 in agroinfiltrated plants by His -Tag ELISA, positive control: His-Tag Standard and negative control: protein extracted from Wild-type $(\mathrm{p} \leq 0.01)$

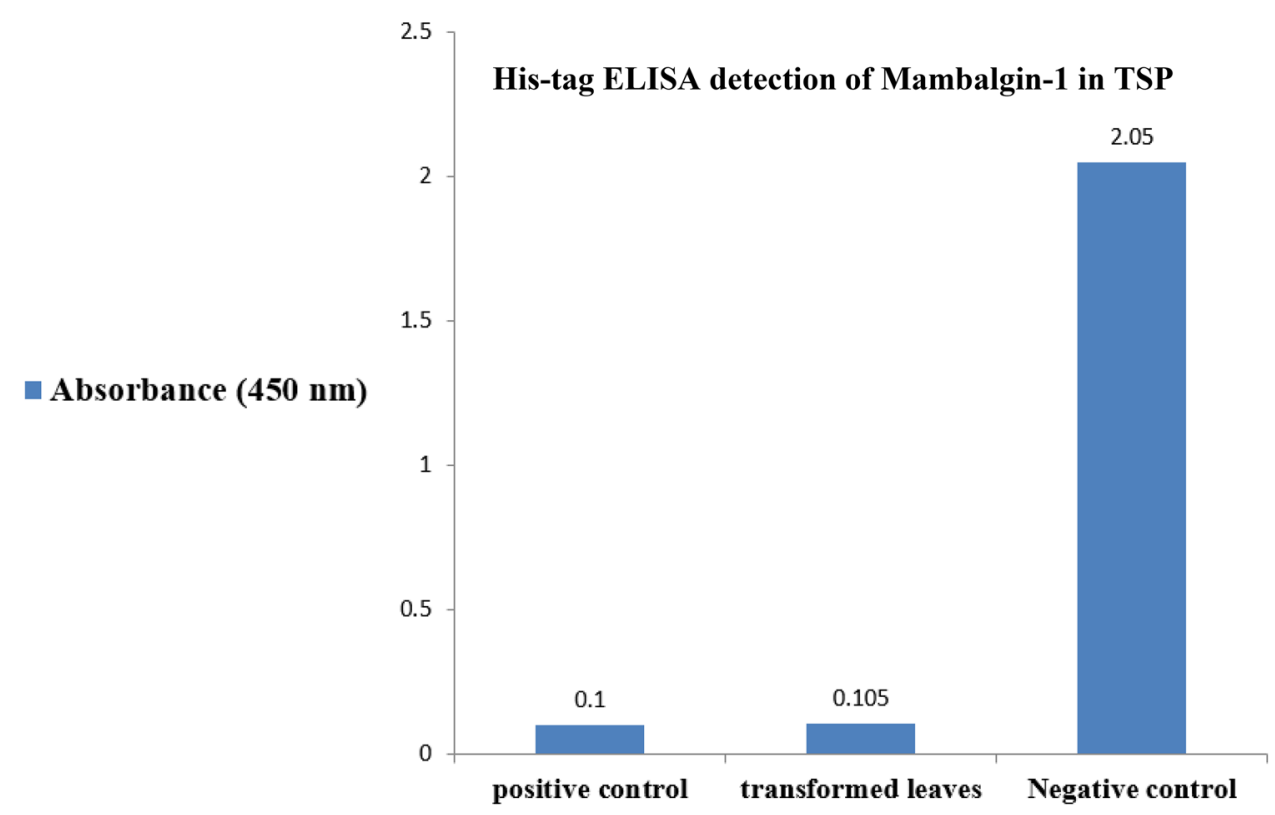


Fig. 4 Quantification and Confirmation of purified Mambalgin- 1 by His-Tag ELISA, positive control: His -Tag Standard and negative control: Dialysis gin-1 $(\mathrm{p} \leq 0.01)$ buffer used to purify Mambal-

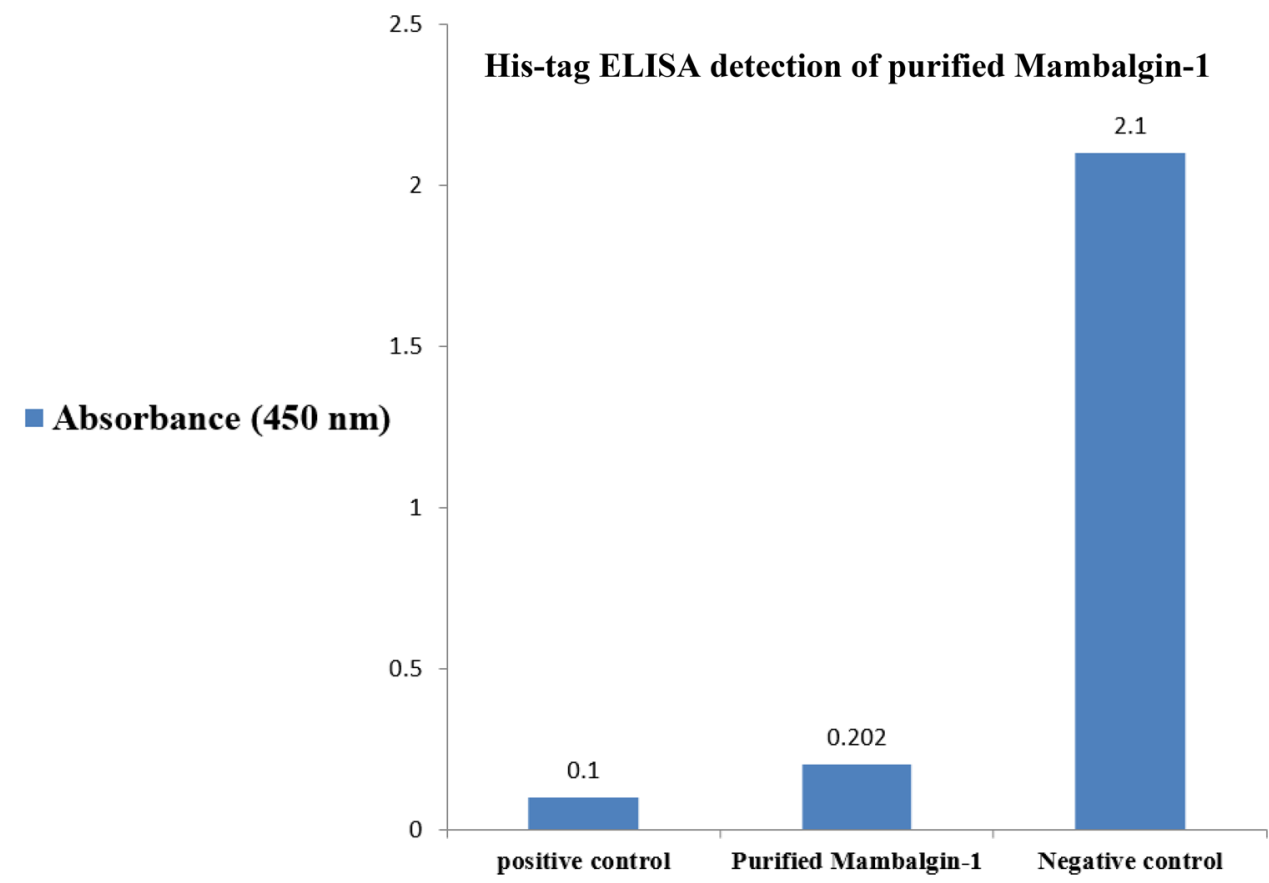

Detection (Fig. 4) and its concentration estimated $37 \mu \mathrm{g} / \mathrm{ml}$. various studies have been performed to produce recombinant proteins in $N$. benthamiana with a transient expression system based on PVX virus vectors. For example, the production of granulocyte macrophage colony stimulating factor (GM-CSF) protein by pPVX201 vector in the amount of $2 \%$ TSP has been reported by Zhou et al. (2006). In 2007, the recombinant apoptotic protein (candidate for the Chicken anemia virus vaccine) was reported to be $5.4 \%$ of TSP by PVX-GW vector (Lacorte et al. 2007). In a study with PVX-GW viral vector, recombinant green fluorescent protein (GFP) protein was expressed in the amount of $3 \%$ TSP (Lacorte et al. 2007). Mardanova et al. were able to enhance the expression of M2eHBc (influenza vaccine candidate) up to $10 \%$ of TSP by modifying the pA7248AMV vector (based on genetic elements of potato virus $\mathrm{X}$ ) and constructing the pEff vector (Mardanova et al. 2017). In this study, we quantified the expression of recombinant Mambalgin-1 in TSP by competitive His-Tag ELISA. For competitive His-Tag ELISA, the concentration of TSP was diluted 240 times to reach $15 \mu \mathrm{g} / \mathrm{ml}$. After ELISA, the optical absorption was shown to be 0.105 and using the absorbance of standard kit solutions, the amount of Mambalgin-1 was $690 \mathrm{ng} / \mathrm{ml}$. Taking into account the dilution is carried out, the amount of Mambalgin- 1 in TSP, $165 \mu \mathrm{g} / \mathrm{ml}$ (4.5\% TSP) is calculated, therefore, regarding five times dilution of TSP, the recombinant Mambalgin- 1 was expressed as $0.825 \mathrm{~g}$ per $\mathrm{kg}$ of fresh leaf tissue. The purified protein was diluted in the same ratio (based on TSP concentration) and its optical absorption was 0.202 and its concentration was $160 \mathrm{ng} / \mathrm{ml}$ (obtained by standard optical absorption kit) and by calculating the dilution, its concentration was $37 \mu \mathrm{g} / \mathrm{ml}$.

\section{Biological activity of Mambalgin-1 in TSP and its purified form}

Figures 5 and 6 show the cytotoxicity of the serial dilution of total protein extracted from agroinfiltrated and nonagroinfiltrated $N$. benthamiana in the human cell culture containing SH-SY5Y and MCF7 cancer cells in MTT testing. As shown in Fig. 5, after 48 h, Mambalgin-1 (treatment) in all diluted concentrations had cytotoxic effects on SH-SY5Y cells, while the cytotoxic effects of control 1 and control 2 were reduced at concentrations $1 / 128$ and 1/256 $(\mathrm{p}<0.01)$. Figure 6 shows that the cytotoxicity of control 1 was greater than control 2 and treatment $(\mathrm{p}<0.01)$ on MCF7 cancer cells after $48 \mathrm{~h}$ and the cytotoxicity of control 2 and treatment had no significant difference $(\mathrm{p}<0.01)$. Recent studies on the production of anticancer recombinant proteins in the plant using a transient expression system in Nicotiana benthamiana can be attributed to the production of the Limulus polyphemus anti-lipopolysaccharide factor $_{32-51}$-E7 or $\mathrm{LALF}_{32-51}$-E7 vaccine against human papillomavirus E7 (HPV E7) (Causes 5\% of all cancers worldwide) (Plummer et al. 2016; Yanez et al. 2018, 2017), production of anti-cancer antibodies such as CO17-1A, Ofatumumab and Rituximab (Jin et al. 2019; Kommineni et al. 2019; Song et al. 2018) and production of Viscumin anti-cancer therapeutic protein (Gengenbach et al. 2019). Another anticancer therapeutic protein has recently been produced in tomatoes using the same system by Beihaghi and et al. (Beihaghi et al. 2018). According to the results in Figs. 5 and 6, the Mambalgin-1 had a cytotoxic effect on SH-SY5Y cells, but no cytotoxic effect seen on MCF7 cancer cells. Figure 7 shows 


\section{Cytotoxicity of serial dilution of TSP on SH-SY5Y cells}

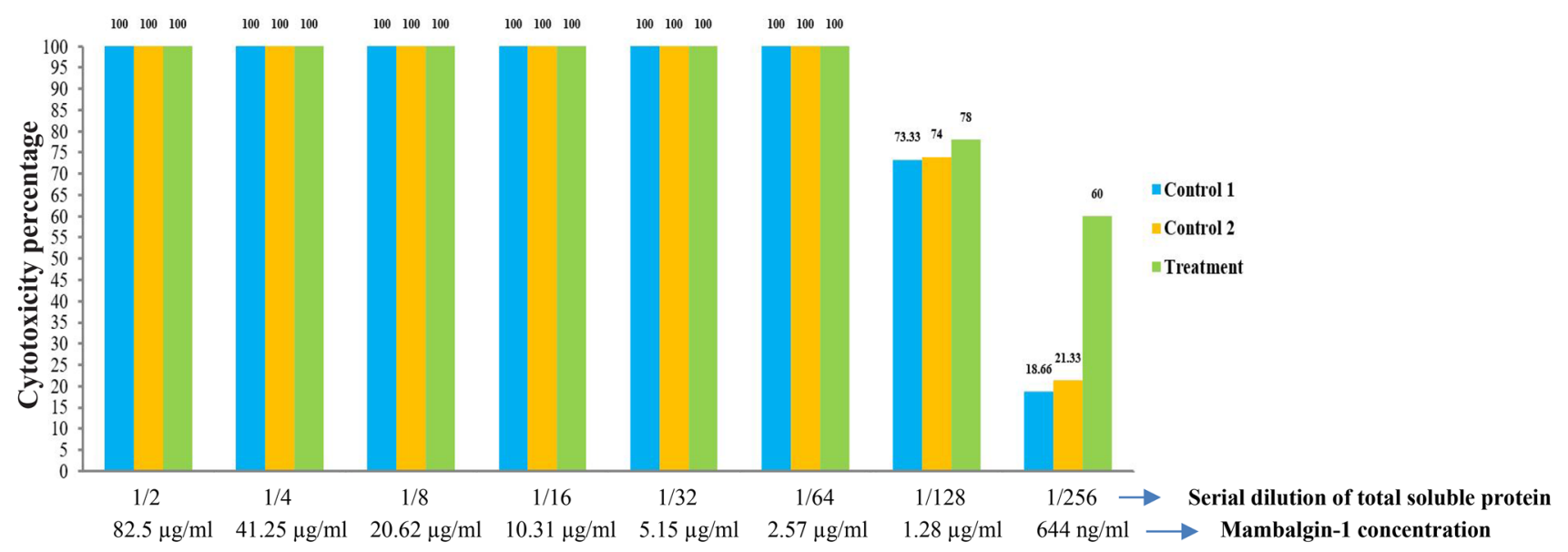

Fig. 5 Cytotoxicity percentage of the serial dilution of the total protein extracted from agroinfiltrated and non-agroinfiltrated Nicotiana benthamiana in cell culture containing SH-SY5Y neural cancer cells in MTT test, Control 1: total protein extracted from non-agroinfiltrated Nicotiana benthamiana, Control 2: total protein extracted from agroinfiltrated Nicotiana benthamiana by Agrobacterium tumefaciens strain GV3101 containing PVX vector (without Mambalgin-1 gene) and Agrobacterium harboring the P19 silencing-suppressor, Treatment: total protein extracted from agroinfiltrated Nicotiana benthamiana by Agrobacterium tumefaciens strain GV3101 containing PVX-Mambalgin-1 and Agrobacterium harboring the P19 silencingsuppressor $(\mathrm{p} \leq 0.01)$

\section{Cytotoxicity of serial dilution of TSP on MCF7 cells}

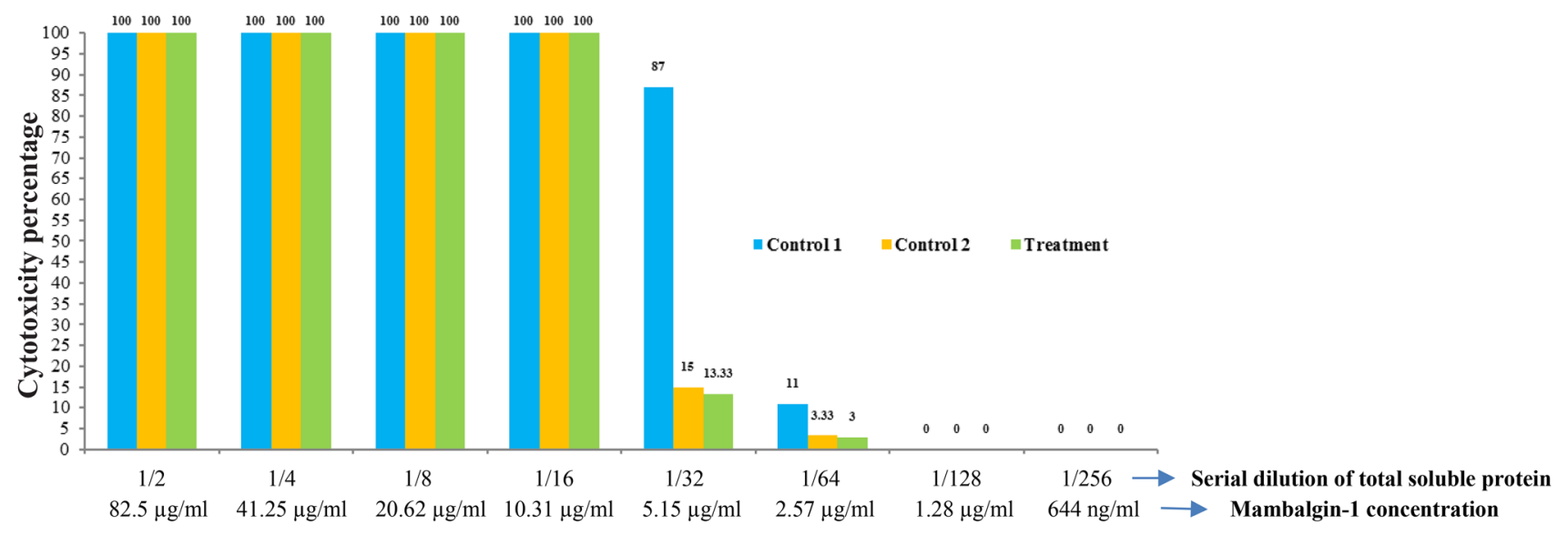

Fig. 6 Cytotoxicity percentage of the serial dilution of the total protein extracted from agroinfiltrated and non-agroinfiltrated Nicotiana benthamiana in cell culture containing MCF7 breast cancer cells in MTT test, Control 1: total protein extracted from non-agroinfiltrated Nicotiana benthamiana, Control 2: total protein extracted from agroinfiltrated Nicotiana benthamiana by Agrobacterium tumefaciens

the cytotoxicity of the serial dilution of purified Mambalgin-1 for SH-SY5Y and MCF7 cancer cells in MTT assay. The results show that cytotoxicity of negative control was higher than of Mambalgin-1 $(5 \mu \mathrm{g} / \mathrm{ml})$ and did not differ significantly in lower concentrations in MCF7 cancer cells $(\mathrm{p}<0.01)$. Also, in $5 \mu \mathrm{g} / \mathrm{ml}$ concentration, cytotoxicity of purified Mambalgin-1 on mesophilic cells (MSC) is more than MCF7 cells. Therefore, according to the results, strain GV3101 containing PVX vector (without Mambalgin-1 gene) and Agrobacterium harboring the P19 silencing-suppressor, Treatment: total protein extracted from agroinfiltrated Nicotiana benthamiana by Agrobacterium tumefaciens strain GV3101 containing PVX-Mambalgin-1 and Agrobacterium harboring the P19 silencingsuppressor $(\mathrm{p} \leq 0.01)$

purified Mambalgin-1 does not have cytotoxic effects on MCF7 cancer cells. At all concentrations, the cytotoxic effect of purified Mambalgin-1 on SH-SY5Y cancer cells is higher than the negative control and MSC cells. ASIC is a proton-gated cation channel mainly expressed in nerve cells and belongs to the degenerin/epithelial $\mathrm{Na}+$ channel (DEG/ $\mathrm{ENaC}$ ) superfamily (Krauson et al. 2018; Wu et al. 2017b). Various studies have shown that these channels contribute 


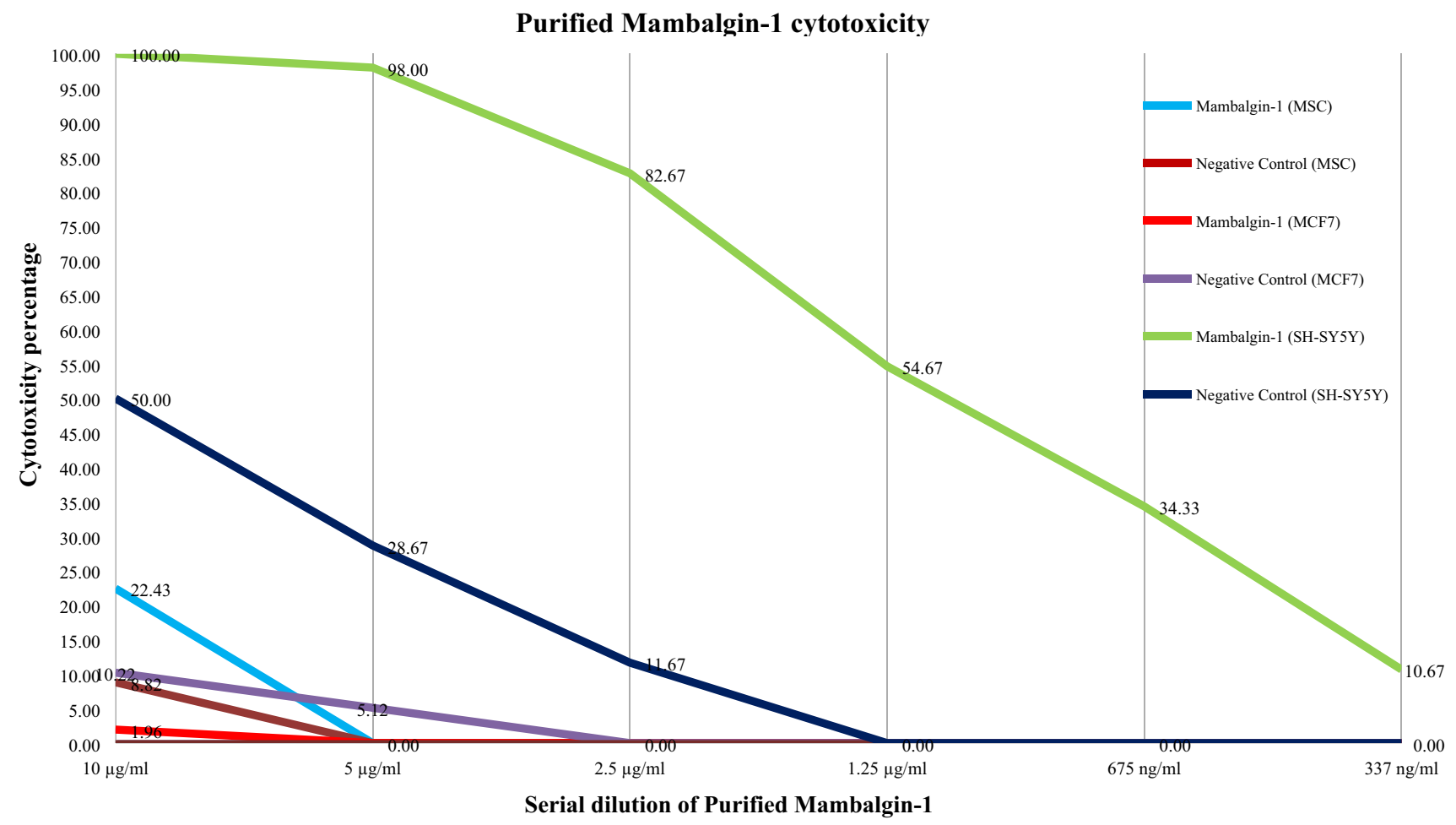

Fig. 7 Cytotoxicity percentage of the serial dilution of purified Mambalgin-1 for MCF7 breast cancer cells, SH-SY5Y nervous cancer cells and MSC mesophilic cells in MTT test, Negative Control: Dialysis buffer used to purify Mambalgin-1 ( $\mathrm{p} \leq 0.01)$

to the progression, proliferation, and migration of cancer cells such as glioblastoma, breast and lung cancer cells. By inhibiting these channels with inhibitors such as amiloride and PcTx-1, the growth, proliferation, and migration of cancer cells were decreased (Baron and Lingueglia 2015; Gupta et al. 2016; Wu et al. 2017a). Since Mambalgin-1 is a potent inhibitor of ASIC channels (Diochot et al. 2016), which are overexpressed in and, promote the proliferation and growth of cancer cells (Baron and Lingueglia 2015; Gupta et al. 2016; Wu et al. 2017a), we conducted MTT testing on two types of neural SH-SY5Y and breast MCF7 cancer cells. To minimize the cytotoxic effect of the buffer and cell components in treatment and controls, and to show the cytotoxic effect of Mambalgin-1, total protein concentration was serially reduced in the rows. As is seen in Fig. 5, the treatment had more cytotoxicity on SH-SY5Y cells at concentrations of $1 / 128$ and $1 / 256(p<0.01)$, indicating the cytotoxic effect of Mambalgin-1 on SH-SY5Y cells. Results of Fig. 5 shows that the cytotoxicity of control 1 and control 2 is probably due to the presence of protein extraction buffer and the remaining cellular components. In Fig. 6, the cytotoxicity of wells with concentrations lower than $1 / 32$ was reduced. At dilutions of $1 / 32$ and $1 / 64$, the cytotoxicity of control 1 with control 2 and treatment was different $(\mathrm{p}<0.01)$. There was no difference in cytotoxicity between control 2 and treatment, indicating that Mambalgin-1 had no cytotoxic effect on MCF7 cancer cells. Control 1 had a higher cytotoxicity, which may be due to the remaining protective substances of agro-infiltration medium in total protein from control 2 and treatment. According to the results of the MTT assay for TSP, the same results obtained for purified Mambalgin-1 in the MTT assay (Fig. 7). Figure 7 shows Mambalgin-1 has a more cytotoxic effect on SH-SY5Y cells than the negative control and mesophilic cells $(\mathrm{p}<0.01)$ while it has no cytotoxic effect on MCF7 cancer cells $(p<0.01)$. Therefore, in this study, Mambalgin-1 had a cytotoxic effect on SHSY5Y neuronal cells, but did not influence MCF7 cancer cells. ASIC channels were activated with extracellular $\mathrm{pH}$ and were involved in the pathogenesis of glioma and breast cancer tumors. Also, the expression level of RNA and protein of ASIC channels in A549 cancer cells increased with extracellular acidity, followed by an increase in the proliferation and migration of these cancer cells (Wu et al. 2017a). Research has shown that the acidity of breast cancer tumor microenvironment triggers the activation of ASIC channels, followed by the growth and proliferation of cancerous cells (Gupta et al. 2016; Wu et al. 2017a). Inhibition of ASIC1a (One of the ASIC channel subunits) in glioblastoma cells by the stopping cell cycle kills these cells (Kapoor et al. 2009; Rooj et al. 2012). Given the fact that acidity activates the ASICs channels, and non-acidic pH of the MTT assay medium and extracted protein; it can, therefore, concluded 
that ASICs channels in MCF7 cancer cells are not activated, and there was no target for Mambalgin-1 in order to inhibit them. As SH-SY5Y cells derive from the neuronal stem cells and the ASICs are typically expressed in neurons (Krauson et al. 2018), it is probable that Mambalgin-1 has stopped the cell cycle and induced the death of these cells by inhibiting the ASIC1a channels.

\section{Conclusions}

Du to removing transformation and tissue culture time and expenses and required labor it is cost-effective to use transient expression systems based on viral vectors to produce recombinant proteins. We were able to express the Mambalgin-1 protein using this system and the PVX-GW viral vector cost-effectively. The recombinant protein extracted from the plant inoculated with PVX expressing Mambalgin-1 has cytotoxicity on SH-SY5Y neural cancer cells with no effect on MCF7 breast cancer cells. Results show that Mambalgin-1 is biologically active with potential anticancer activity.

Author contributions GK, SJD, BBKR conceived and designed the method adopted in this study. GK, SJD with assistance by HO performed the method and analyzed the data.. All authors contributed to the writing of the manuscript. All the authors read and approved the final manuscript.

\section{References}

Ahn J-W, Lee JS, Davarpanah SJ, Jeon J-H, Park Y-I, Liu JR, Jeong WJ (2011) Host-dependent suppression of RNA silencing mediated by the viral suppressor p19 in potato. Planta 234:1065-1072. https:// doi.org/10.1007/s00425-011-1465-1

Barahimipour R, Strenkert D, Neupert J, Schroda M, Merchant SS, Bock R (2015) Dissecting the contributions of GC content and codon usage to gene expression in the model alga Chlamydomonas reinhardtii. Plant $\mathrm{J} 84: 704-717$

Baron A, Lingueglia E (2015) Pharmacology of acid-sensing ion channels - physiological and therapeutical perspectives. Neuropharmacology 94:19-35. https://doi.org/10.1016/j.neuropharm .2015.01.005

Beihaghi M, Marashi H, Bagheri A, Sankian M (2018) Transient expression of CCL21 as recombinant protein in tomato. Biotechnol Rep 17:10-15. https://doi.org/10.1016/j.btre.2017.11.007

Bradford MM (1976) A rapid and sensitive method for the quantitation of microgram quantities of protein utilizing the principle of protein-dye binding. Anal Biochem 72:248-254. https://doi. org/10.1016/0003-2697(76)90527-3

Brendel V, Kleffe J, Carle-Urioste JC, Walbot V (1998) Prediction of splice sites in plant pre-mRNA from sequence properties. J Mol Biol 276:85-104. https://doi.org/10.1006/jmbi.1997.1523

Buyel J, Kaever T, Buyel J, Fischer R (2013) Predictive models for the accumulation of a fluorescent marker protein in tobacco leaves according to the promoter/5' UTR combination. Biotechnol Bioeng 110:471-482. https://doi.org/10.1002/bit.24715
Carbone A, Zinovyev A, Képes F (2003) Codon adaptation index as a measure of dominating codon bias. Bioinformatics 19:2005-2015. https://doi.org/10.1093/bioinformatics/btg272

Diochot $\mathrm{S}$ et al (2016) Analgesic effects of mambalgin peptide inhibitors of acid-sensing ion channels in inflammatory and neuropathic pain. Pain 157:552-559. https://doi.org/10.1097/j.pain.00000 00000000397

Diochot $\mathrm{S}$ et al (2012) Black mamba venom peptides target acid-sensing ion channels to abolish pain. Nature 490:552-555. https://doi. org/10.1038/nature11494

Fahad S et al (2015) Recent developments in therapeutic protein expression technologies in plants. Biotechnol Lett 37:265-279. https://doi.org/10.1007/s10529-014-1699-7

Gengenbach BB et al (2019) Comparison of microbial and transient expression (tobacco plants and plant-cell packs) for the production and purification of the anticancer mistletoe lectin viscumin. Biotechnol Bioeng 116:2236-2249. https://doi.org/10.1002/bit.27076

Gupta $S$ et al (2016) Regulation of breast tumorigenesis through acid sensors. Oncogene 35:4102. https://doi.org/10.1038/onc.2015.477

Hefferon KL (2012) Plant virus expression vectors set the stage as production platforms for biopharmaceutical proteins. Virology 433:1-6. https://doi.org/10.1016/j.virol.2012.06.012

Hefferon K (2017) Plant virus expression vectors: a powerhouse for global health. Biomedicines 5:44. https://doi.org/10.3390/biome dicines5030044

Hellens R, Mullineaux P, Klee H (2000) Technical focus: a guide to Agrobacterium binary Ti vectors. Trends Plant Sci 5:446-451

Institute S (2012) SAS/STAT 12.1 User's Guide: Survey Data Analysis (book Excerpt). SAS Institute Incorporated

Jin $\mathrm{N}$ et al (2019) Low binding affinity and reduced complementdependent cell death efficacy of ofatumumab produced using a plant system (Nicotiana benthamiana L.). Protein Express Purif 159:34-41. https://doi.org/10.1016/j.pep.2019.03.004

Jung S-K, McDonald K (2011) Visual gene developer: a fully programmable bioinformatics software for synthetic gene optimization Bmc. Bioinformatics 12:340. https://doi. org/10.1186/1471-2105-12-340

Kapoor N, Bartoszewski R, Qadri YJ, Bebok Z, Bubien JK, Fuller CM, Benos DJ (2009) Knockdown of ASIC1 and epithelial sodium channel subunits inhibits glioblastoma whole cell current and cell migration. J Biol Chem 284:24526-24541. https://doi. org/10.1074/jbc.M109.037390

Kommineni $\mathrm{V}$ et al (2019) In vivo glycan engineering via the mannosidase I inhibitor (Kifunensine) improves efficacy of rituximab manufactured in Nicotiana benthamiana plants. Int J Mol Sci 20:194. https://doi.org/10.3390/ijms20010194

Kopertekh L, Schiemann J (2019) Transient production of recombinant pharmaceutical proteins in plants: evolution and perspectives. Curr Med Chem 26:365-380. https://doi.org/10.2174/0929867324 666170718114724

Krauson AJ, Rooney JG, Carattino MD (2018) Molecular basis of inhibition of acid sensing ion channel $1 \mathrm{~A}$ by diminazene. PLoS ONE 13:e0196894. https://doi.org/10.1371/journal.pone.0196894

Lacorte C, Lohuis H, Goldbach R, Prins M (2007) Assessing the expression of chicken anemia virus proteins in plants. Virus Res 129:80-86. https://doi.org/10.1016/j.virusres.2007.06.020

Laemmli UK (1970) Cleavage of structural proteins during the assembly of the head of bacteriophage T4. Nature 227:680-685. https ://doi.org/10.1038/227680a0

Leuzinger K, Dent M, Hurtado J, Stahnke J, Lai H, Zhou X, Chen Q (2013) Efficient agroinfiltration of plants for high-level transient expression of recombinant proteins. JoVE. https://doi. org/10.3791/50521

Liao YD, Jeng JC, Wang CF, Wang SC, Chang ST (2004) Removal of $\mathrm{N}$-terminal methionine from recombinant proteins by engineered E. coli methionine aminopeptidase. Protein Sci 13:1802-1810 
Loh H-S, Green BJ, Yusibov V (2017) Using transgenic plants and modified plant viruses for the development of treatments for human diseases. Curr Opin Virol 26:81-89. https://doi. org/10.1016/j.coviro.2017.07.019

Love AJ, Chapman SN, Matic S, Noris E, Lomonossoff GP, Taliansky M (2012) In planta production of a candidate vaccine against bovine papillomavirus type 1. Planta 236:1305-1313. https://doi. org/10.1007/s00425-012-1692-0

Mardanova ES, Blokhina EA, Tsybalova LM, Peyret H, Lomonossoff GP, Ravin NV (2017) Efficient transient expression of recombinant proteins in plants by the novel $\mathrm{pEff}$ vector based on the genome of potato virus X. Front Plant Sci 8:247. https://doi. org/10.3389/fpls.2017.00247

Margolin E, Chapman R, Williamson AL, Rybicki EP, Meyers AE (2018) Production of complex viral glycoproteins in plants as vaccine immunogens. Plant Biotechnol J 16:1531-1545. https://doi. org/10.1111/pbi.12963

Moghaddam MM, Barjini KA, Ramandi MF, Amani J (2014) Investigation of the antibacterial activity of a short cationic peptide against multidrug-resistant Klebsiella pneumoniae and Salmonella typhimurium strains and its cytotoxicity on eukaryotic cells. World J Microbiol Biotechnol 30:1533-1540. https://doi.org/10.1007/ s11274-013-1575-y

Mohammadzadeh S, Khabiri A, Roohvand F, Memarnejadian A, Salmanian AH, Ajdary S, Ehsani P (2014) Enhanced-transient expression of hepatitis $\mathrm{C}$ virus core protein in Nicotiana tabacum, a protein with potential clinical applications. Hepatitis Mon. https ://doi.org/10.5812/hepatmon.20524

Mohammadzadeh S, Roohvand F, Memarnejadian A, Jafari A, Ajdary S, Salmanian A-H, Ehsani P (2016) Co-expression of hepatitis $\mathrm{C}$ virus polytope-HBsAg and $\mathrm{p} 19$-silencing suppressor protein in tobacco leaves. Pharm Biol 54:465-473. https://doi. org/10.3109/13880209.2015.1048371

Mourier G et al (2016) Mambalgin-1 pain-relieving peptide, stepwise solid-phase synthesis, crystal structure, and functional domain for acid-sensing ion channel 1a inhibition. J Biol Chem 291:26162629. https://doi.org/10.1074/jbc.M115.702373

Nakamura Y, Gojobori T, Ikemura T (1998) Codon usage database: https://www.kazusa.or.jp/codon. Nucleic Acids Res 26:334

Narsai R, Howell KA, Millar AH, O’Toole N, Small I, Whelan J (2007) Genome-wide analysis of mRNA decay rates and their determinants in Arabidopsis thaliana. Plant Cell 19:3418-3436. https:// doi.org/10.1105/tpc.107.055046

Nielsen H (2017) Predicting secretory proteins with SignalP. In: Kihara D (ed) Protein function prediction. Springer, New York, pp 59-73

Obembe OO, Popoola JO, Leelavathi S, Reddy SV (2011) Advances in plant molecular farming. Biotechnol Adv 29:210-222. https:// doi.org/10.1016/j.biotechadv.2010.11.004

Payne G, Ahl P, Moyer M, Harper A, Beck J, Meins F, Ryals J (1990) Isolation of complementary DNA clones encoding pathogenesisrelated proteins $\mathrm{P}$ and $\mathrm{Q}$, two acidic chitinases from tobacco. Proc Natl Acad Scie USA 87:98-102. https://doi.org/10.1073/ pnas.87.1.98

Petersen TN, Brunak S, von Heijne G, Nielsen H (2011) SignalP 4.0: discriminating signal peptides from transmembrane regions. Nat Methods 8:785. https://doi.org/10.1038/nmeth.1701

Plummer M, de Martel C, Vignat J, Ferlay J, Bray F, Franceschi S (2016) Global burden of cancers attributable to infections in 2012: a synthetic analysis. Lancet Glob Health 4:e609-e616. https://doi. org/10.1016/S2214-109X(16)30143-7

Rooj AK, McNicholas CM, Bartoszewski R, Bebok Z, Benos DJ, Fuller CM (2012) Glioma-specific cation conductance regulates migration and cell cycle progression. J Biol Chem 287:4053-4065. https ://doi.org/10.1074/jbc.M111.311688
Rybicki E (2018) History and promise of plant-made vaccines for animals. In: MacDonald J (ed) Prospects of plant-based vaccines in veterinary medicine. Springer, New York, pp 1-22

Rychlik W (2007) OLIGO 7 primer analysis software. In: PCR primer design. Springer, pp 35-59. https://doi.org/10.1007/978-1-59745 $-528-2 \_2$

Salinas M, Besson T, Delettre Q, Diochot S, Boulakirba S, Douguet D, Lingueglia E (2014) Binding site and inhibitory mechanism of the mambalgin-2 pain-relieving peptide on acid-sensing ion channel 1a. J Biol Chem 289:13363-13373. https://doi.org/10.1074/jbc. M114.561076

Shamloul M, Trusa J, Mett V, Yusibov V (2014) Optimization and utilization of Agrobacterium-mediated transient protein production in Nicotiana. JoVE. https://doi.org/10.3791/51204

Song I, Kang Y, Lee YK, Myung S-C, Ko K (2018) Endoplasmic reticulum retention motif fused to recombinant anti-cancer monoclonal antibody (mAb) CO17-1A affects $\mathrm{mAb}$ expression and plant stress response. PLoS ONE. https://doi.org/10.1371/journ al.pone.0198978

Tamura K, Dudley J, Nei M, Kumar S (2007) MEGA4: molecular evolutionary genetics analysis (MEGA) software version. Mol Biol Evol 24:1596-1599. https://doi.org/10.1093/molbev/msm092

Unger T, Peleg Y (2012) Recombinant protein expression in the baculovirus-infected insect cell system. In: Zanders ED (ed) Chemical genomics and proteomics. Springer, New York, pp 187-199

Weigel D, Glazebrook J (2006) Transformation of agrobacterium using the freeze-thaw method. CSH Protoc 2006:1031-1036. https://doi. org/10.1101/pdb.prot4666

Wu Y, Gao B, Xiong Q-J, Wang Y-C, Huang D-K, Wu W-N (2017a) Acid-sensing ion channels contribute to the effect of extracellular acidosis on proliferation and migration of A549 cells. Tumor Biol 39:1010428317705750. https://doi.org/10.1177/1010428317 705750

Wu Y, Gao B, Xiong Q-J, Wang Y-C, Huang D-K, Wu W-N (2017b) Acid-sensing ion channels contribute to the effect of extracellular acidosis on proliferation and migration of A549 cells. Tumor Biol 39:1-8. https://doi.org/10.1177/1010428317705750

Xiong Z-G, Pignataro G, Li M, Chang S-y, Simon RP (2008) Acidsensing ion channels (ASICs) as pharmacological targets for neurodegenerative diseases. Curr Opin Pharmacol 8:25-32. https:// doi.org/10.1016/j.coph.2007.09.001

Yamamoto T et al (2018) Improvement of the transient expression system for production of recombinant proteins in plants. Sci Rep 8:1-10. https://doi.org/10.1038/s41598-018-23024-y

Yanez RJ, Lamprecht R, Granadillo M, Weber B, Torrens I, Rybicki EP, Hitzeroth II (2017) Expression optimization of a cell membrane-penetrating human papillomavirus type 16 therapeutic vaccine candidate in Nicotiana benthamiana. PLoS ONE. https://doi. org/10.1371/journal.pone.0183177

Yanez RJ et al (2018) LALF32-51-E7, a HPV-16 therapeutic vaccine candidate, forms protein body-like structures when expressed in Nicotiana benthamiana leaves. Plant Biotechnol J 16:628-637. https://doi.org/10.1111/pbi.12802

Zhou F, Wang M-L, Albert HH, Moore PH, Zhu YJ (2006) Efficient transient expression of human GM-CSF protein in Nicotiana benthamiana using potato virus $\mathrm{X}$ vector. Appl Microbiol Biotechnol 72:756-762. https://doi.org/10.1007/s00253-005-0305-2

Publisher's Note Springer Nature remains neutral with regard to jurisdictional claims in published maps and institutional affiliations. 